\title{
FORMAÇÃO DE PROFESSORES PARA O ENSINO MÉDIO INTEGRADO À EDUCAÇÃO PROFISSIONAL
}

\author{
TEACHER TRAINING FOR SECONDARY EDUCATION INTEGRATED WITH \\ VOCATIONAL EDUCATION
}

DOI: $\underline{\text { 10.23926/RPD.2526-2149.2020.v5.n2.p1329-1341.id717 }}$

\section{Ana Lúcia de Figueiredo \\ Mestranda em Educação \\ Profissional e Tecnológica \\ (ProfEPT) \\ Assistente de Laboratório na Universidade Federal do Triangulo Mineiro (UFTM). alfigueiredo2013@gmail.co $\underline{\mathrm{m}}$}

\section{Ana Sara Castaman \\ Doutora em Educação (UNISINOS) \\ Professora no Instituto \\ Federal do Rio Grande do Sul (IFRS). \\ ana.castaman@sertao.ifrs.ed u.br}

\section{Josimar de Aparecido Vieira}

Doutor em Educação (PUCRS)

Professor no Instituto

Federal do Rio Grande do Sul (IFRS)

josimar.vieira@sertao.ifrs.ed u.br
Resumo: O presente ensaio objetiva conhecer os conceitos e os fundamentos do Ensino Médio Integrado à Educação Profissional (EMIEP), de modo a examinar as peculiaridades desta modalidade de ensino visando à formação de professores que nela atuam. Assim, a partir de uma revisão bibliográfica pautada em autores que se ocupam com a temática do EMIEP, apresenta-se: as acepções e as bases conceituais do EMIEP no Brasil; a formação de professores diante do Currículo Integrado. Como considerações finais, salientase que ainda há inúmeros desafios na implementação do EMIEP no Brasil e a necessidade de proposições, contudo há que se preocupar com a formação dos professores que atuam nesta modalidade de ensino para que possam articular práticas pedagógicas que mediam a formação humana e técnica, a partir de um currículo que harmonize o mundo do trabalho ao contexto em que os sujeitos estão inscritos. Palavras-chave: Ensino médio integrado. Formação de professores. Currículo integrado.

\begin{abstract}
This essay aims to understand the concepts and fundamentals of Integrated High School to Professional Education (EMIEP), in order to examine the peculiarities of this teaching modality aiming at the formation of teachers who work in it. Thus, based on a bibliographic review based on authors who deal with the theme of EMIEP, we present: the meanings and conceptual bases of EMIEP in Brazil; teacher training in the face of the integrated curriculum. As final considerations, it should be noted that there are still numerous challenges in the implementation of EMIEP in Brazil and the need for propositions, however it is necessary to be concerned with the training of teachers who work in this type of teaching so that they can articulate pedagogical practices that mediate training human and technical, from a curriculum that harmonizes the world of work with the context in which the subjects are enrolled.
\end{abstract}

Keywords: Integrated high school. Teacher training. Integrated curriculum. 


\title{
1 INTRODUÇÃO
}

A proposta do Ensino Médio Integrado à Educação Profissional (EMIEP) é 'bem brasileira', adaptada à realidade do país (KUENZER, 2010). Frigotto (2013) enfatiza que o EMIEP implica em uma formação técnica e profissional permitindo “dupla base". Dito de outro modo, a primeira relacionada à 'cidadania política', à forma para a participação, à conscientização e à intervenção do indivíduo na sociedade. A segunda intitulada 'cidadania econômica', prepara científica e tecnicamente com qualidade e aprofundamentos que possibilitam o domínio das técnicas de produção (FRIGOTTO, 2013).

No que se refere à formação específica de professores que atuam no EMIEP, deverá orientar-se nas proposições do Currículo Integrado. Santomé (1998) explana que a nominação Currículo Integrado tem sido empregada como um esforço para o entendimento global do conhecimento e da promoção da interdisciplinaridade na sua construção. À integração implica unir as inúmeras e diferentes unidades curriculares e os modos de conhecimento nas instituições escolares. Castaman e Hannecker (2017) reforçam que independente das divergências teóricas sobre a integração, as propostas construídas têm em comum o exame à organização disciplinar. Na concepção de Ciavatta e Ramos (2012, p. 309-310):

\begin{abstract}
O currículo integrado - ou o currículo do ensino médio integrado - destaca a organização do conhecimento como um sistema de relações de uma totalidade histórica e dialética. Ao integrar, por um lado, trabalho ciência e cultura, tem-se a compreensão do trabalho como mediação primeira da produção da existência social dos homens, processo esse que coincide com a própria formação humana, na qual conhecimento e cultura são produzidos. O currículo integrado elaborado sobre essas bases não hierarquiza os conhecimentos nem os respectivos campos das ciências, mas os problematiza em suas historicidades, relações e contradições.
\end{abstract}

Ciavatta (2005) traz considerações acerca do Currículo Integrado afirmando que para às escolas desenvolverem um projeto real de ensino integrado será preciso que lhes seja permitido produzir seu próprio Projeto Político Pedagógico (PPP) respeitando a sua identidade e a sua autonomia no desenvolvimento de seu planejamento educacional. Além disso, de acordo com Santos (2017), para formação dos 'futuros' professores será necessário a adequação dos currículos das licenciaturas, tendo em vista a formação de docentes pesquisadores, capazes de atuar no enfrentamento da realidade escolar, a partir de uma performance didáticometodológica condizente com as demandas do processo de ensino e aprendizagem do EMIEP.

Para tanto, o professor carece inteirar-se das propostas norteadoras do EMIEP, das diretrizes e das perspectivas do trabalho docente. Diante disso, considerando a inexistência de cursos de formação específicos para atuação no EMIEP, urge chamar a atenção dos docentes que trabalham nesta modalidade de ensino e de futuros formadores, para conhecer e estudar o 
projeto organizacional do Currículo Integrado, além de ressaltar para a imprescindibilidade de políticas públicas de formação, que os prepararem para o desempenho no EMIEP.

Diante dessas considerações iniciais, está constituído o teor desse artigo em que se buscou conhecer os conceitos e os fundamentos do Ensino Médio Integrado à Educação Profissional, de modo a examinar as peculiaridades desta modalidade de ensino visando à formação de professores que nela atuam. Pauta-se na técnica bibliográfica, orientada em autores que se ocupam com o estudo da temática do EMIEP. Optou-se por este referencial teórico, porque entende-se que se trata de uma proposta articulada e com vistas à educação emancipatória. Assim, o presente artigo está dividido em 02 partes: a) discorre as acepções e as bases conceituais do EMIEP no Brasil; b) aborda acerca da formação de professores diante do Currículo Integrado. Por fim, apresenta as considerações finais.

\section{Metodologia}

Considerando seu propósito, este estudo caracteriza-se como pesquisa exploratória e descritiva. Sampieri, Collado e Lúcio (2006) afirmam que as pesquisas exploratórias visam a examinar um tema pouco estudado, enquanto a pesquisa descritiva busca especificar propriedades e características importantes do fenômeno analisado. Desenvolveu-se a partir de uma abordagem que se assenta predominantemente numa perspectiva qualitativa e dialética, seguindo os movimentos e as contradições próprios dos espaços educativos. A pesquisa qualitativa trabalha com o universo de significados, motivos, aspirações, crenças, valores e atitudes, o que corresponde a uma profundidade das relações, dos processos e dos fenômenos que não podem ser reduzidos à operacionalização de variáveis (MINAYO, 2002).

Fundamentou-se a técnica bibliográfica, a partir de material já publicado, constituído principalmente de livros, de artigos de periódicos e, atualmente, de material disponibilizado na internet, com incidência em obras de autores: Ciavatta (2005, 2014), Cêa (2007), Saviani (2007, 2009), Moura (2007, 2008, 2010, 2014), Ramos (2008), Frigotto (2012, 2013, 2016), Vieira e Vieira (2019), Silva e Santos (2020), Silva e Souza (2020), entre outros. Ainda, apresentou-se alguns documentos como subsídios para a escrita: Brasil (1996, 1997, 2004).

\section{O ENSINO MÉDIO INTEGRADO À EDUCAÇÃO PROFISSIONAL}

Na Lei no 9.394/1996 (BRASIL, 1996), Lei de Diretrizes e Bases da Educação Brasileira (LDB), documento orientador de elaboração da política de Ensino Médio e da Educação 
Profissional, verifica-se dados que atrelam a formação profissional integrada à geral. Contudo, a reforma da educação profissional pautou-se no Decreto $n^{\circ}$ 2.208/1997 (BRASIL, 1997) que, conforme Cêa (2007), instiga a dualidade entre a formação geral e profissional. Tentando amenizar e/ou reparar ambiguidades nas políticas para o Ensino Médio e à Educação Profissional, revogou-se o Decreto $n^{\circ} 2.208$ (BRASIL, 1997) e aprova-se o Decreto $\mathrm{n}^{\circ} 5.154$ (BRASIL, 2004), em 23 de julho de 2004. De acordo com o Decreto $n^{\circ} 5.154$, que estabelece as diretrizes e bases da educação nacional, e dá outras providências,

Art. $4^{\circ}$ A educação profissional técnica de nível médio, nos termos dispostos no $\S 2^{\circ}$ do art. 36, art. 40 e parágrafo único do art. 41 da Lei no 9.394, de 1996, será desenvolvida de forma articulada com o ensino médio [...] § $1^{\circ} \mathrm{A}$ articulação entre a educação profissional técnica de nível médio e o ensino médio dar-se-á de forma: I integrada [...] (BRASIL, 2004).

Assim, no EMIEP “[...] o estudante faz um curso único que lhe diploma tanto com o ensino médio quanto com um curso profissionalizante, $[\ldots]$, um curso único, com um projeto pedagógico, para a formação integrada e paralela" (VIEIRA; VIEIRA, 2019, p. 05). Nesta concepção, propõe-se que o ensino médio possa ocorrer de forma integrada à uma educação técnica, profissional e tecnológica e que, nesse caso, teríamos o EMIEP, atribuindo personalidade e aumentando a sua oferta em âmbito nacional (MOURA, 2014).

O EMI seria uma base unitária que respeita a diversidade da realidade social, oferecendo aos alunos a formação básica e profissional na qual não basta aprender o conhecimento técnico operacional e apenas saber fazer. É necessário ter a compreensão global do processo e da tecnologia que executa para saber o porquê de fazer uma atividade de determinada forma (SILVA; SANTOS, 2020, p. 03).

Deste modo, resguardadas as normas do sistema de ensino, as instituições escolares acrescentam "[...] ao mínimo exigido para o ensino médio, uma carga horária destinada à formação específica para o exercício de profissões técnicas, ou para a iniciação científica, ou para a ampliação da formação cultural” (RAMOS, 2008, p. 10), de forma integrada. Não obstante, de acordo com Ciavatta (2005) é preciso ponderar muito bem o que vem a ser essa formação integrada. A autora apresenta considerações sobre o que é integrar:

É tornar íntegro, tornar inteiro, o quê? A palavra toma sentido moral em alguns usos correntes. Mas não é disso que se trata aqui. Remetemos o termo ao seu sentido de completude, de compreensão das partes no seu todo ou da unidade do diverso, de tratar a educação como uma totalidade social, isto é, nas múltiplas mediações históricas que concretizam os processos educativos. No caso da formação integrada ou do ensino médio integrado ao ensino técnico, queremos que a educação geral se torne parte inseparável da educação profissional em todos os campos onde se dá a preparação para o trabalho [...] (CIAVATTA, 2005, p. 84).

Moura (2007) elucida que não há como falar em integração sem abranger a formação integral ou omnilateral do ser humano que têm no trabalho, na ciência, na tecnologia e na 
cultura, os elementos indissociáveis para sua constituição. Por formação omnilateral compreende-se uma educação que se ocupe de "todas as dimensões que constituem a especificidade do ser humano e as condições objetivas e subjetivas reais para seu pleno desenvolvimento histórico" (FRIGOTTO, 2012, p. 267). Nesse sentido, a formação integrada pode conduzir os seres humanos à uma educação unitária direcionada a preparar o homem para ações de planejamento e de direção, suplantando o conceito histórico-social do trabalho operacional apartado da formação intelectual (CIAVATTA, 2005).

Para Ramos (2008), a educação unitária é considerada 'direito de todos', o que implica o acesso universal ao conhecimento, a cultura e as demais intervenções que permitam a realização do trabalho, a garantia de sobrevivência e a geração de riqueza para a sociedade. Almeja-se, por meio da formação integral fomentar nos estudantes posturas de tolerância e de capacidade para a tomada de decisão democrática, consolidando princípios de racionalidade na percepção do mundo e tornando-os conscientes da complexidade do mundo, da diversidade e da relatividade da cultura (SACRISTAN, 2013). Nesse caso, Frigotto (2016) alude que a educação básica deve garantir esta formação integral ou omnilateral, a partir da politecnia.

Etimologicamente, politecnia significa 'muitas técnicas'. No Brasil, o termo, com esse sentido, deu nome a instituições educacionais como escolas de engenharia (a Escola Politécnica da Universidade de São Paulo); e com o sentido voltado para a formação humana em todos os aspectos, a educação omnilateral, humanista e científica, como a Escola Politécnica de Saúde Joaquim Venâncio (EPSJV-Fiocruz). Na segunda interpretação do termo, há um sentido político, emancipatório no sentido de superar, na educação, a divisão social do trabalho entre trabalho manual/trabalho intelectual, e formar trabalhadores que possam ser, também, dirigentes no sentido gramsciano (CIAVATTA, 2014, p. 189-190).

Para Silva e Souza (2020, p. 14) "Uma proposta politécnica de educação possibilita que o estudante se fundamente nos conhecimentos basilares das ciências naturais, sociais, da linguagem, da cultura, de modo que ele consiga transitar pelo mundo do trabalho com plasticidade e autonomia". Frigotto (2016) ressalta que um ensino integrado como 'travessia' para a politecnia, vai além da interdisciplinaridade, pois a realidade é única e não fragmentada. A integração remete à Educação Profissional e Tecnológica (EPT) para uma concepção que vai além da simples formação para o trabalho, abarcando uma formação histórica e científica, típica da 'práxis' humana que possibilita aos indivíduos o desenvolvimento de autonomia crítica na prática de uma profissão (RAMOS, 2008).

De acordo com Moura (2010), o PPP em uma perspectiva de integração, altera a função social da instituição que passa a considerar a dimensão do trabalho na formação do currículo. O autor propõe em sua investigação, um modelo de organização do currículo do EMIEP, a 
saber: núcleo comum integrador das três áreas do ensino médio, sendo uma parte variada com conteúdos que aludem ao mundo do trabalho, a formação profissional específica e a prática profissional.

Neste caso, os autores aqui citados admitem que o trabalho deve se constituir como um princípio educativo. Segundo Moura (2007), o trabalho como princípio educativo em sua 'dimensão ontológica e histórica', direciona o ser humano a construir sua participação na sociedade. A dimensão ontológica do trabalho envolve dois sentidos que, primeiramente, caracterizam o trabalho como realização humana e, após, atribuem-lhe o sentido econômico, com a comercialização da força do trabalho representado na sociedade do capital pelo contrato de emprego. Nessa lógica, o trabalho e a ciência constituem uma singularidade. Isto posto, entende a dimensão do trabalho como princípio educativo, que molda a realidade do ser humano, que pode a qualquer momento transformá-la (RAMOS, 2008).

No Ensino Médio, a dimensão educativa do trabalho influenciará sua organização de forma unitária, a fim de superar um ensino que não garante ao estudante compreender a ciência a partir de sua própria realidade. Entende-se que se constitui princípio educativo enquanto demonstrar aos estudantes que o trabalho é atributo de todos e que as relações sociais de trabalho não podem ser construídas por meio de sua exploração injusta e desenfreada (CIAVATTA, 2005).

Para Moura (2010), a importância da implantação do EMIEP está em permitir aos jovens da classe trabalhadora possibilidades de inserção social e, além disso, que, a longo prazo, com o auxílio da pesquisa tecnológica, criar um conceito de ciência e de tecnologia nacional, agregando valores para o país e influenciando na mudança das finalidades da educação. O EMIEP é também uma forma de democratizar a educação, facilitando que a classe trabalhadora tome consciência do valor do trabalho, alterando sua realidade e transformando-a (MOURA, 2010).

Nesse sentido, o EMIEP deverá ser capaz de proporcionar ao estudante uma formação que propicie a construção do conhecimento e a aplicação das diferentes técnicas produtivas, bem como os fundamentos científicos que embasam esses recursos, concedendo aos jovens ao final dessa modalidade de ensino engajar-se no mundo do trabalho ou mesmo no prosseguimento em direção à formação universitária (SAVIANI, 2007). Neste escopo, há que se pensar que os docentes que atuam no EMIEP precisam estar preparados para mediar o processo de ensino e aprendizagem diante de suas bases conceituais. Destarte, é necessário investir na formação de professores, a qual está repleta de desafios. 


\title{
4 FORMAÇÃO DE PROFESSORES PARA O ENSINO MÉDIO INTEGRAdO À EDUCAÇÃo PROFISSIONAL: CONSIDERAÇÕES
}

As mudanças desencadeadas pelo homem no seu projeto de vida e no mundo social, coloca em questão e, como centro de preocupação, as propostas existentes de formação de professores. Marques (2000, p. 11) destaca que:

\begin{abstract}
Em especial, a organização e condução dos cursos de formação do educador são tarefas muito concretas e circunstanciadas, que importa sejam desconstruídas a cada passo, isto é, decompostas e analisadas, e sejam reconstituídas pelos próprios cursos, isto é, pelos agentes/atores neles envolvidos e nos diversos níveis em que se definem e operacionalizam. [...] ver [...] a formação/atuação do educador [...] como situadas no mundo social-humano de que fazem parte e como relações produzidas por alteridades internas irredutíveis umas às outras [...].
\end{abstract}

Saviani (2009) chama atenção para o modelo atual das licenciaturas e da formação continuada de professores e dos profissionais da educação. O curso de licenciatura, por exemplo, inclui além das unidades curriculares de metodologia, o estágio obrigatório que, muitas vezes, executa-se somente no papel. Na prática, fica a cargo dos professores das escolas, aceitarem os estudantes ou simplesmente assinarem como se os estágios tivessem sido realizados. À vista disso, deveria haver uma escola laboratório (SAVIANI, 2009) específica para formação de docentes, direcionada a reproduzir as vivências da profissão docente na formação dos futuros profissionais.

Ademais, todo candidato a docente deveria, além da formação específica em determinada área do conhecimento, cursar uma formação pedagógica ou um curso de pedagogia, ou ainda um curso de mestrado para atuar em toda a educação básica, visto que apenas os saberes específicos em determinada área do conhecimento, não capacita os profissionais para atuarem na formação integral dos alunos, a qual vai muito além de conteúdos de disciplinas. Outrossim, as políticas públicas em sua maioria, são deficitárias e mudam a todo o momento, causando descontinuidades. Geralmente não se tem a educação como prioridade, como bem salientou Saviani (2009).

Na EPT, as indagações, as fragilidades e os desafios são ainda maiores, pois para Moura (2014) o currículo clássico não gradua professores para atuar na docência, considerando a existência de um EMIEP. Há pelo menos três perfis atuando na EPT, de: profissionais bacharéis e tecnólogos que não realizaram na formação inicial licenciatura; profissionais bacharéis e tecnólogos que realizaram o curso de formação pedagógica para graduados não licenciados; e professores licenciados. Mesmo diante desse quadro, grande parte dos docentes que atuam nessa modalidade de ensino, não compreendem os sentidos da integração deste projeto particular e específico. 
Essas divergências encontradas na estrutura organizacional e formativa dos profissionais da EPT podem representar desafios para a prática pedagógica, para as necessidades e para as demanda no/do EMIEP, já que poderá haver um desencontro dialógico com o mundo do trabalho, com as " "...] práticas pedagógicas interdisciplinares e contextualizadas, perspectiva de emancipação do educando, trabalho como princípio educativo e interação com a tecnologia, ciência e cultura" (SILVA; SANTOS, 2020, p. 05). É preciso então, conforme Moura (2007), que haja a reconstrução do entendimento coletivo sobre o EMIEP e uma adequação dos professores em seu espaço e tempo, para trabalharem de forma integrada e interdisciplinar com os demais professores e disciplinas. Marques (2000, p. 39) apesar de não tratar em sua obra sobre o EMIEP, faz uma consideração que cabe neste momento para pensar acerca da reconstrução da formação de professores:

\begin{abstract}
Em se tratando da reconstrução, em novas bases prático-teóricas, dos cursos de formação de educadores, torna-se necessário, antes ainda, aprofundar o entendimento comum sobre o que seja a dimensão profissional no mundo de hoje, sobre o que devemos entender por formação profissional em sua relevância fundamente e sobre que linhas temático-conceituais deve embasar-se a formação profissional da educação em sua qualidade de coletivo dos educadores.
\end{abstract}

Diante dessa complexidade, é preciso refletir acerca das perspectivas de formação docente, almejando a formação integral do aluno. Moura (2008) reforça que o professor é um dos elementos fundamentais para a formação integral do estudante.

Nesse processo educativo, o professor deve assumir outra atitude, forjada a partir de outro tipo de formação, que deve ser crítica, reflexiva e orientada pela responsabilidade social. Nessa perspectiva, o docente deixa de ser um transmissor de conteúdos acríticos e definidos por especialistas externos para assumir uma atitude problematizadora e mediadora do processo ensino-aprendizagem sem, no entanto, perder sua autoridade nem, tampouco, a responsabilidade com a competência técnica dentro de sua área do conhecimento (MOURA, 2008, p. 30).

Moura (2014) orienta que para o projeto de EMIEP faz-se necessário uma formação coerente dos docentes, de modo que este assuma sua identidade de classe e de trabalhador, gerando empatia nos formados por ele, já que a formação docente não ocorre somente nos espaços formais, mas deve levar em conta a carga social em que o mesmo está inserido. Por isso, é fundamental ser um intelectual consciente de sua participação social.

Assim, os núcleos estruturantes para a formação docente necessitam integrar os eixos: conhecimento específico e formação didático-pedagógica, dialogando com a sociedade, o mundo do trabalho e a educação (MOURA, 2014). Esses dois eixos associados à interdisciplinaridade poderão proporcionar mudanças significativas, desde que, se apreenda os sentidos de uma prática interdisciplinar. 
A interdisciplinaridade refere-se ao diálogo com outras disciplinas sem perder o foco de conhecimento das mesmas, efetivado por meio de projetos integradores que envolvam pesquisa, visando a encontrar soluções para problemas locais, regionais e até mundiais. Tais ações proporcionam a possibilidade de aquisição de 'autonomia intelectual' por parte dos estudantes a eles vinculados (MOURA, 2014).

Para Ramos (2008), a interdisciplinaridade permite reunir os conhecimentos das ciências em suas especificidades de forma a estabelecer relações de significado, que facilitam a compreensão das ideias, dos fundamentos e do métodos reais, utilizando-os para o desenvolvimento pessoal e social. A fragmentação das disciplinas do currículo, individualizadas e desvinculadas da realidade não permitem sua compreensão. Destarte, é preciso que haja uma adequação dos professores em seu espaço e tempo, para trabalharem de forma integrada e interdisciplinar com os demais professores e unidades curriculares.

Logo, a formação de professores, seja inicial, seja continuada, necessita atentar para essas questões que norteiam o Currículo Integrado, promovendo a ampliação das possibilidades e das referências vitais dos indivíduos; deve ensejar uma formação e um desenvolvimento profissional do grupo de professores (MOURA, 2014) que atua no âmbito das Instituições da EPT, pautado à reflexão de noções que subsidiem o trabalho docente. Essa formação dos educadores,

[...] deve privilegiar a formação no âmbito das políticas públicas do país, principalmente as educacionais, numa perspectiva de superação do modelo de desenvolvimento socioeconômico vigente, de modo que se deve priorizar mais o ser humano do que, simplesmente, as relações de mercado e o fortalecimento da economia (MOURA, 2008, p. 30).

Outrossim, o professor que atua no EMIEP,

[...] licenciado, bacharel ou tecnólogo, precisa de uma profunda fundamentação científica referente à sua área. Contudo, esse conhecimento não pode estar comparti mentado, encaixotado, isolado: esse professor precisa estabelecer relações entre a especificidade de seu conhecimento e a globalidade do fazer social, entre a dimensão teórica de sua área de estudos e a concretude do que se pratica; entre sua disciplina, as outras disciplinas e as aplicações concretas destas no "mundo real" que é o mundo do trabalho. Neste sentido, pensamos que o professor licenciado tenha bastante a aprender com o bacharel que atuou (ou ainda atua) profissionalmente em áreas diversas antes de abraçar a docência. O professor do EMI precisa ter clareza a respeito da racionalidade pedagógica. [...]. (SILVA; SOUZA, 2020, p. 17).

Ressalta-se que hodierno, existem ofertas de formação docente, como programas especiais, cursos de pós-graduação e formação a distância, contudo são “[...] muito reduzidas considerando o potencial de demanda e nem sempre atendem a todos os perfis de entrada dos candidatos" (MACHADO, 2008, p. 14). Trata-se então, de proporcionar aos atuais e futuros 
docentes uma formação que privilegie o humano e a ressonância aos conhecimentos e as bases conceituais que norteiam a atuação no EMIEP. Um espaço formativo no qual todos possam reconhecer a responsabilidade no exercício profissional, perceber-se como "[...] potenciais agentes mediadores de aprendizagem e valorizar suas produções" (FERNANDES, 2018, p. 49), bem como assumir uma atitude problematizadora, emancipatória e articuladora dos conhecimentos específicos, didático-político-pedagógico e dialógico com o social e com o mundo do trabalho.

\section{CONSIDERAÇÕES FinAIS}

Ao longo do texto procurou-se empreender análises da realidade conjuntural do EMIEP e que estão diretamente relacionadas à formação de professores. Assim, apresentou-se primeiramente as definições de integração e como essas concepções orientam a constituição do EMIEP, com vistas a uma formação integral do ser humano nas dimensões científicas culturais e tecnológicas, tendo o trabalho como princípio educativo. A seguir, refletiu-se acerca da formação de professores alinhadas à essa modalidade educacional.

$\mathrm{O}$ exposto no texto demonstrou que a mediação do professor é fundamental, diante de uma proposta de formação integral para o EMIEP, que supera a dualidade do ensino e que almeja a autonomia dos educandos, mediante a formação geral para a vivência social e para o mundo do trabalho. Assim, é preciso um programa de formação específica para atuação no EMIEP, que envolvam além de políticas públicas de incentivo e de orientação, o esforço coletivo de gestores e de professores, com o intuito de preparar o docente para atender às demandas do Currículo Integrado. Salienta-se que ainda há inúmeros desafios na implementação do EMIEP no Brasil, contudo há que se preocupar com a formação dos professores que atuam nesta modalidade de ensino para que possam articular práticas pedagógicas que mediam a formação humana e técnica, a partir de um currículo que harmonize o mundo do trabalho ao contexto em que os sujeitos estão inscritos.

Essas constatações acompanhadas das discussões realizadas nesse material textual recomendam outras buscas teóricas e análises de dados acerca dos processos formativos dos docentes, incluindo a perspectiva da pesquisa como princípio educativo, outro conceito estruturante do EMIEP. Reconhece-se inacabada essa reflexão, sobretudo, porque com os apontamentos empreendidos atingiu-se apenas o limiar do que se constitui a finalidade deste texto. Contudo, lança-se o desafio e o convite para novas investigações e para rediscutir a 
formação dos professores que atuam no EMIEP, bem como para refletir as reformas na esfera federal e desdobramentos nos currículos integrados estaduais.

\section{REFERÊNCIAS}

BRASIL. Lei Federal no 9.394, de 20 de dezembro de 1996. Estabelece as diretrizes e bases da educação nacional. Disponível em: https://www.cpt.com.br/ldb/lei-de-diretrizes-e-basesda-educacao-completa-interativa-e-atualizada?gclid=EAIaIQobChMInf_wY6s6AIVhxGRCh01PA6cEAAYASAAEgLPb_D_BwE. Acesso em: 24 maio 2020.

BRASIL. Decreto n o 2.208, de 17 de abril de 1997. Regulamenta o $§ 2^{\circ}$ do art. 36 e os Arts. 39 a 42 da Lei Federal no 9.394/1996, que estabelece as Diretrizes e Bases da Educação Nacional. Disponível em: https://www.camara.leg.br/proposicoesWeb/prop_mostrarintegra;jsessionid=58C28967B18B C95534748230382E9775.proposicoesWebExterno2? codteor $=106035 \&$ filename $=$ LegislacaoC itada+-PL+7375/2002. Acesso em: 24 maio 2020.

BRASIL. Decreto 5.154, de 23 de julho de 2004. Regulamenta o $\S 2^{\circ}$ do art. 36 e os arts. 39 a 41 da Lei n $^{\circ}$ 9.394, de 20 de dezembro de 1996, que estabelece as Diretrizes e Bases da Educação Nacional, e dá outras providências. Disponível em:

http://www.planalto.gov.br/ccivil_03/_ato2004-2006/2004/decreto/d5154.htm. Acesso em: 24 maio 2020.

CASTAMAN, Ana Sara; HANNECKER, Lenir Antonio. Currículo Integrado: pensando o ensino integrado nos Institutos Federais de Educação, Ciência e Tecnologia no Brasil. Revista de Estudos e Pesquisas sobre Ensino Tecnológico (Educitec). Manaus, 5, 48-57, 2017. Disponível em: https://sistemascmc.ifam.edu.br/educitec/index.php/educitec/article/view/245. Acesso em: 24 maio 2020.

CÊA, Geórgia Sobreira dos Santos. (Org.). O estado da arte da formação do trabalhador no Brasil. Pressupostos e ações governamentais a partir dos anos 1990. Cascavel: EDUNIOESTE, 2007.

CIAVATTA, Maria A. Formação integrada: a escola e o trabalho como lugares de memória e de identidade. In: FRIGOTTO, Gaudêncio; RAMOS, Marise Nogueira; CIAVATTA, Maria. (Orgs.) Ensino Médio Integrado: Concepção e contradições. São Paulo: Cortez, 2005

CIAVATTA, Maria. O ensino integrado, a politecnia e a educação omnilateral. Por que lutamos? Trabalho \& Educação, Belo Horizonte, v. 23, n.1, p. 187-205, 2014. Disponível em:

http://forumeja.org.br/go/sites/forumeja.org.br.go/files/Ciavatta_ensino_integrado_politecnia_ educacao_omnilateral.pdf Acesso em: 24 maio 2020.

CIAVATTA, Maria; RAMOS, Marise. Ensino médio integrado. In: CALDART, Roseli Salete; PEREIRA, Isabel Brasil; ALENTEJANO, Paulo; FRIGOTTO, Gaudêncio (org). Dicionário da Educação do campo. Rio de Janeiro, São Paulo: Escola Politécnica de Saúde Joaquim Venâncio, Expressão Popular. 2012. p. 307-315.

FERNANDES, Manoela Wendler. A formação continuada dos profissionais da educação na educação profissional e tecnológica: o lugar ocupado pelo social. In: CASTAMAN, Ana Sara; 
VIEIRA, Josimar de Aparecido Vieira. Gestão da Educação Profissional e Tecn ológica: elementos para reflexão. 1 ed. Curitiba: CRV, 2018.

FRIGOTTO, Gaudêncio. Educação Omnilateral. In: CALDART, Roseli Salete; PEREIRA, Isabel Brasil; ALENTEJANO, Paulo; FRIGOTTO, Gaudêncio (org). Dicionário da Educação do campo. Rio de Janeiro; São Paulo: Escola Politécnica de Saúde Joaquim Venâncio, Expressão Popular. 2012. p. 267-274.

FRIGOTTO, Gaudêncio. Entrevista realizada no programa Educação em Pauta, pela TV Câmara. [Arquivo de Vídeo], 30 nov. 2013. Disponível em: Portal EMI, https://sites.google.com/view/portalemi/v\%C3\%ADdeos?authuser=0. Acesso em: 24 maio 2020.

FRIGOTTO, Gaudêncio. Ensino Integrado, Politecnia e Institutos Federais: por que lutamos? Mesa redonda no auditório do Instituto Federal Fluminense (IFF). [Arquivo de Vídeo], 15 abr. 2016. Disponível em: Portal EMI, https://sites.google.com/view/portalemi/v\%C3\%ADdeos?authuser=0. Acesso em: 24 maio 2020.

KUENZER, Acácia Zeneida. Palestra, em 4 partes, realizada no I Seminário Temático do Programa de Desenvolvimento Educacional. Programa Hora Atividade veiculado pela TV Paulo Freire. [Arquivo de Vídeo], 2010. Disponível em: Portal EMI, https://sites.google.com/view/portalemi/v\%C3\%ADdeos?authuser=0. Acesso em: 08 maio 2020.

MACHADO, Lucília Regina de Souza. Diferenciais inovadores na formação de professores para a educação profissional. Revista Brasileira da Educação Profissional e Tecnológica, Brasília, v. 1, n. 1, p. 8-22, 2008. Disponível em: http://portal.mec.gov.br/setec/arquivos/pdf3/rev_brasileira.pdf. Acesso em: 04 maio 2020.

MARQUES, Mário Osório. Formação do profissional da educação. 3 ed. Ijuí: Unijuí, 2000.

MINAYO, Maria Cecília de Souza. (org.) Pesquisa social: teoria, método e criatividade. 21 ed. Rio de Janeiro: Vozes, 2002.

MOURA, Dante Henrique. Educação básica e educação profissional e tecnológica: dualidade histórica e perspectivas de integração. Holos, Natal, v. 2, n. 23, p. 4-30, 2007. Disponível em: http://www2.ifrn.edu.br/ojs/index.php/HOLOS/article/view/11. Acesso em: 05 maio 2020.

MOURA, Dante Henrique. A formação de docentes para a educação profissional e tecnológica. Revista Brasileira da Educação Profissional e Tecnológica, Natal, v. 1, n. 1, p. 23-38, 2008.

MOURA, Dante Henrique. Nós da Educação. Programa veiculado pela TV Paulo Freire, em 3 partes. [Arquivo de Vídeo], 2010. Disponível em: Portal EMI, https://sites.google.com/view/portalemi/v\%C3\%ADdeos?authuser=0. Acesso em: 10 maio 2020.

MOURA, Dante Henrique. Trabalho e formação docente na educação profissional. 1. ed. Curitiba: Instituto Federal do Paraná, 2014. 
RAMOS, Marise Nogueira. Concepção do ensino médio integrado. Texto apresentado em seminário promovido pela Secretaria de Educação do Estado do Pará, 08 e 09 de maio, 2008. Disponível em: https://tecnicadmiwj.files.wordpress.com/2008/09/texto-concepcao-doensino-medio-integrado-marise-ramos1.pdf. Acesso em: 19 maio 2020.

SACRISTÀN, José Gimeno. O que significa o currículo? In: SACRISTÀN, José Gimeno. (Org.). Saberes e incertezas sobre o currículo. Porto Alegre: Penso, 2013.

SAMPIERI, Roberto Hernandez; COLLADO, Carlos Fernández; LUCIO, Maria Del Pilar Baptista. Tipos de Pesquisa. In: SAMPIERI, Roberto Hernandez; COLLADO, Carlos Fernández; LUCIO, Maria Del Pilar Baptista. Metodologia da pesquisa. 3 ed. São Paulo: McGraw-Hill, 2006.

SANTOMÉ, Jurjo Torres. Globalização e interdisciplinaridade: o currículo integrado. Porto Alegre: Artes Médicas, 1998.

SANTOS, Sandra Regina Rodrigues dos. Visitando a literatura que trata sobre a formação de professores (as). Pesquisa em Foco, São Luís, v. 22, n. 1, p. 215-247, 2017. Disponível em: http://ppg.revistas.uema.br/index.php/PESQUISA_EM_FOCO. Acesso em: 20 maio 2020.

SAVIANI, Demerval. Trabalho e educação: fundamentos ontológicos e históricos. Revista Brasileira de Educação, Rio de Janeiro, v. 12, n. 34, p.152-180, 2007. Disponível em: http://www.scielo.br/pdf/rbedu/v12n34/a12v1234.pdf. Acesso em: 20 maio 2020.

SAVIANI, Demerval. Formação de professores: aspectos históricos e teóricos do problema no contexto brasileiro. Revista Brasileira de Educação, Rio de Janeiro, v. 14, n. 40, p. 143-155, 2009. Disponível em: http://www.scielo.br/pdf/rbedu/v14n40/v14n40a12.pdf Acesso em: 20 maio 2020.

SILVA, Claudia Maria Bezerra da; SANTOS, Edlamar Oliveira dos. Formação Continuada do Professor do Ensino Médio Integrado: concepções e importância. Revista Brasileira da Educação Profissional e Tecnológica, Natal, v. 1. N. 18, 1-15, 2020. Disponível em: http://www2.ifrn.edu.br/ojs/index.php/RBEPT/article/view/9281. Acesso em: 20 maio 2020.

SILVA, Priscila Tiziana Seabra Marques da; SOUZA, Francisco das Chagas Silva. Docência no ensino médio integrado: compromisso com as demandas do mercado ou com a formação humana integral? Revista Humanidades e Inovação, Palmas, v. 7, n. 1, p. 09-20, abr. 2020.

VIEIRA, Josimar de Aparecido; VIEIRA, Marilandi Maria Mascarello. Ensino médio integrado à educação profissional: por que insistir nesta forma de ensino? Revista Cocar, Belém, v. 13, n. 26, p. 478-496, 2019. Disponível em:

https://paginas.uepa.br/seer/index.php/cocar/article/view/2522 Acesso em: 20 maio 2020.

Recebido em: 24 de maio de 2020 .

Aprovado em: 21 de julho de 2020. 